\title{
ANATOMIA DO LENHO DE ALLOPHYLUS GUARANITICUS (ST.-HIL.) RADLK. (SAPINDACEAE) ${ }^{1}$
}

\author{
ANELISE MARTA SIEGLOCH ${ }^{2}$ JOSÉ NEWTON CARDOSO MARCHIORI $^{3}$ \\ SIDINEI RODRIGUES DOS SANTOS ${ }^{4}$
}

\section{RESUMO}

É anatomicamente descrita, de acordo com IAWA (1989), a madeira de Allophylus guaraniticus (St.-Hil.) Radlk., com base em material coletado no município de Barracão, Rio Grande do Sul. A madeira apresenta: poros em curtos múltiplos radiais, solitários e racemiformes, pequenos, muito numerosos; elementos vasculares de comprimento médio, com placas de perfuração simples; pontoações areoladas pequenas; parênquima axial paratraqueal-escasso; raios heterogêneos uni e bisseriados; fibras curtas, tipicamente septadas; e cristais romboédricos em câmaras.

Palavras-chave: Anatomia da madeira, Allophylus guaraniticus, Sapindaceae.

\section{ABSTRACT}

[Wood anatomy of Allophylus guaraniticus (St.-Hil.) Radlk. (Sapindaceae)].

The wood anatomy of Allophylus guaraniticus is described according to IAWA (1989), based on sample collected in the municipality of Barracão, Rio Grande do Sul state (Brazil). The wood structure presents: short radial multiple pores, less commonly solitary or racemiform; medium length vascular elements, with simple perforation plates; small bordered pits; scanty paratracheal parenchyma; unisseriate and bisseriate heterogeneous rays; short septate fibers; and rhombohedrical chambered crystals in the wood.

Key words: Allophylus guaraniticus, Sapindaceae, Wood Anatomy.

\section{INTRODUÇÃO}

Composta por árvores, arbustos e lianas, menos comumente ervas, as Sapindaceae tem distribuição predominantemente tropical e subtropical, havendo poucos gêneros em regiões temperadas (Judd et al., 2009). Na família, é frequente a ocorrência de taninos, saponinas e alcalóides (Schultz,1949; Judd et al., 2009). A flora brasileira abrange 24 gêneros e aproximadamente 400 espécies (Souza \& Lorenzi, 2008), havendo, no Rio Grande do Sul, cinco gêneros arbóreos: Allophylus, Cupania,

\footnotetext{
Recebido para publicação em 14/06/2012 e aceito para publicação em 30/10/2012.

2 Mestranda do Curso de Pós-Graduação em Engenharia Florestal. Bolsista - CAPES. Universidade Federal de Santa Maria, CEP 97105-900. Santa Maria, RS, Brasil. anesiegloch@yahoo.com.br

Engenheiro Florestal, Dr. Bolsista de Produtividade em Pesquisa (CNPq - Brasil). Professor Titular do Departamento de Ciências Florestais, Universidade Federal de Santa Maria. Santa Maria, RS, Brasil.

4 Biólogo, Dr. Núcleo de Estudos Botânicos Balduino Rambo, UFSM.
}

Diatenopteryx, Dodonaea e Matayba (Sobral et al., 2006).

De origem pantropical (Record \& Hess, 1949), o gênero Allophylus apresenta três espécies nas formações florestais sul riograndenses: A. edulis, A. guaraniticus e A. puberulus (Sobral et al., 2008).

Objeto do presente estudo, Allophylus guaraniticus habita, sobretudo, a metade norte do estado (Sobral et al., 2008). Trata-se de arbusto de 2-3 m de altura, que floresce ao final do inverno e primavera e frutifica na primavera e verão. As folhas, compostas, trifoliadas, alternas, com folíolo intermediário peciolado, elíptico, rômbico ou lanceolado (1,5-3 cm x 2,5$7 \mathrm{~cm}$ ), apresenta margem crenada da metade superior, base cuneada e pequenos tricomas na zona apical da lâmina; os folíolos laterais, menores do que o central, são elípticos, subsésseis e com 4-7 pares de nervuras, apresentando margens inteiras ou apenas crenadas (Brussa \& Grela, 2007). 
Com relação à anatomia da madeira, Record \& Hess (1943), Metcalfe \& Chalk (1972) e Baizhong et al. (1995) citam as seguintes características gerais para a família: poros em múltiplos radiais de 2-3 ou solitários, por vezes em pequenos agrupamentos; porosidade difusa; elementos vasculares de comprimento médio a curtos; placas de perfuração simples; pontoações intervasculares alternas, diminutas a pequenas; pontoações raio-vasculares semelhantes às intervasculares; parênquima paratraqueal-escasso, por vezes vasicêntrico; raios unisseriados numerosos, ou com 2-3 células de largura e tipicamente homogêneos, por vezes fracamente heterogêneos; fibras com pontoações simples e tipicamente septadas, de comprimento médio a curtas; e cristais prismáticos em câmaras, no parênquima axial e/ou fibras.

\section{MATERIAL E MÉTODOS}

O material em estudo consiste de uma amostra de madeira e respectivo material botânico, coletados em Barracão - RS, para os quais constam os seguintes registros: Allophylus guaraniticus (St.-Hil.) Radlk. Marchiori, J.N.C., $\mathrm{n}^{\circ}$. 437, 20/08/86 (HDCF).

Para a confecção das lâminas histológicas foram extraídos três corpos de prova $(1 \times 2 \times 3 \mathrm{~cm})$ da parte mais externa do lenho, próxima ao câmbio, orientados para a obtenção de cortes nos planos transversal, longitudinal radial e longitudinal tangencial. Outro bloquinho foi também retirado, com vistas à maceração.

A confecção das lâminas histológicas seguiu a metodologia descrita em Burger \& Richter (1991). No preparo de lâminas de macerado usou-se o método de Jeffrey (Freund, 1970). Os cortes anatômicos foram tingidos com acridinavermelha, crisoidina e azul-de-astra (Dujardin, 1964); o macerado, apenas com safranina $1 \%$. Na montagem das lâminas permanentes usouse Entellan.

As descrições basearam-se nas recomendações do IAWA Committee (1989). No caso da percentagem dos tecidos foram realizadas 600 determinações ao acaso, com auxílio de conta- dor de células, conforme proposto por Marchiori (1980). A abundância de poros foi obtida a partir de um quadrado de área conhecida, superposto a fotomicrografias de seções transversais da madeira.

As medições foram realizadas em microscópio Carl Zeiss, no Laboratório de Anatomia da Madeira da Universidade Federal de Santa Maria. Nas características quantitativas, os números entre parênteses equivalem aos valores mínimos e máximos observados; o valor que acompanha a média é o desvio padrão. As fotomicrografias foram tomadas em microscópio Olympus CX40, equipado com câmera digital Olympus Camedia c3000, no Laboratório de Anatomia da Madeira da Universidade Federal do Paraná.

\section{DESCRIÇÃO ANATÔMICA}

Anéis de crescimento: marcados, geralmente, por camada de 4 fibras em espessura, radialmente estreitas e mais espessas do que as do lenho inicial, bem como por faixas concêntricas de fibras gelatinosas (Figura 1A,B).

Vasos: muito numerosos $(57 \pm 4,5(52-63)$ poros $/ \mathrm{mm}^{2}$ ), ocupando $13 \pm 3,3 \%$ do volume da madeira. Porosidade difusa. Poros em curtos múltiplos radiais (2 a 6), solitários e racemiformes; arredondados $(45 \pm 8(30-60) \mu \mathrm{m})$ e de paredes finas $(3 \pm 0,7(2,5-5) \mu \mathrm{m})$ (Figura 1A,B). Elementos vasculares de comprimento médio $(440 \pm 52(330-530) \mu \mathrm{m})$, com placas de perfuração simples e apêndices em uma ou em ambas as extremidades. Pontoações intervasculares pequenas, arredondadas (4,6 \pm $0,5(4,1-5,1) \mu \mathrm{m})$, alternas, por vezes coalescentes; abertura em fenda elíptica, inclusa, ornamentada. Pontoações raio-vasculares areoladas, com abertura em fenda elíptica $(3,5$ $\pm 0,5(3-4) \mu \mathrm{m})$; por vezes alongadas e aparentemente simples. Conteúdo, frequente. Estrias nas paredes de vasos, presentes (Figura 1C,D).

Parênquima axial: representando 4,8 $\pm 2,3$ $\%$ do volume da madeira e em arranjo paratraqueal-escasso (Figura 1A,B). Séries 


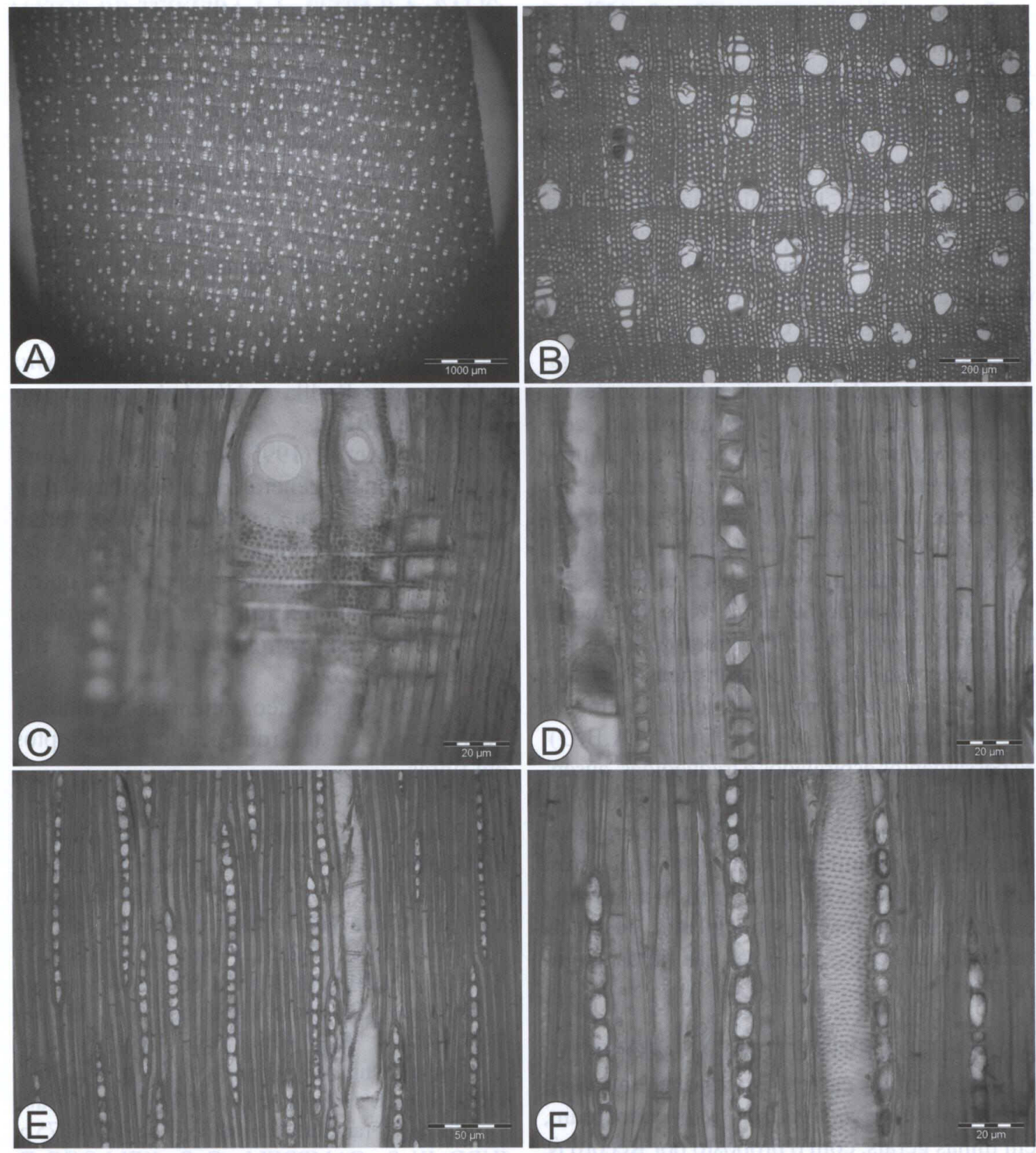

FIGURA 1 - Aspectos anatômicos da madeira de Allophylus guaraniticus (St.-Hil.) Radlk. A - Anéis de crescimento e porosidade difusa (seção transversal). B - Anéis de crescimento marcados por fibras radialmente estreitas, porosidade difusa e vasos em curtos múltiplos radiais, solitários e racemiformes (seção transversal). C - Elementos vasculares com placas de perfuração simples e raio heterocelular (seção longitudinal. radial). D - Seção longitudinal radial, destacando conteúdo em elemento vascular, fibras septadas e cristais romboédricos em câmaras. E - Raios uni e bisseriados, parênquima axial seriado e fibras septadas (seção longitudinal radial). F - Vasos com pontoações intervasculares alternas, raios unisseriados e fibras septadas (seção longitudinal tangencial). 
parenquimáticas de $365 \pm 51(240-455) \mu \mathrm{m}$ de altura, compostas de $3-5$ células (Figura 1E).

Raios: muito numerosos $(13 \pm 2(10-16)$ raios $/ \mathrm{mm}$ ), uni e bisseriados, ocupando $13 \pm 2$ $\%$ do volume da madeira (Figura 1E,F). Os unisseriados, de $381 \pm 136(150-720) \mu \mathrm{m}$ e $6-$ 34 células de altura. Os bisseriados, de $348 \pm$ $147(170-720) \mu \mathrm{m}$ e 8 - 35 células de altura, com margens de 1-16 células; heterocelulares, compõem-se de células procumbentes, no corpo central, e 1-2 fileiras de células quadradas ou eretas, nas margens. Conteúdo e raios fusionados, presentes. Células radiais de paredes disjuntas, células perfuradas, raios agregados, cristais e células envolventes, ausentes.

Fibras: septadas (1-2 septos/fibras), com pontoações areoladas maiores do que $3 \mu \mathrm{m}$ e abertura em fenda elíptica, mais comuns nas faces radiais da parede; curtas ( $805 \pm 80(630-$ 920) $\mu \mathrm{m})$, com $9 \pm 2,9(5-16) \mu \mathrm{m}$ de largura e de paredes finas a espessas $(4,5 \pm 0,6(3,7-$ 5 ,6) $\mu \mathrm{m}$ ), ocupando $69 \pm 5,2 \%$ do volume da madeira (Figura 1A,B,D ). Fibras gelatinosas, em numerosas faixas concêntricas. Cristais romboédricos de aproximadamente $25 \mu \mathrm{m}$, em até 34 câmaras por série (Figura 1A,B,D). Espessamentos espiralados e traqueóides, ausentes.

Outros caracteres: variantes cambiais, tubos laticíferos e taniníferos, canais intercelulares, células oleíferas, células mucilaginosas, estratificação e máculas medulares, ausentes. Inclusões minerais, presentes nas fibras (Figura 1D).

\section{ANÁLISE DA ESTRUTURA ANATÔMICA}

As principais características anatômicas do lenho de Allophylus guaraniticus concordam, em linhas gerais, com o proposto por Record \& Hess (1943), Metcalfe \& Chalk (1972) e Baizhong et al. (1995) para a família Sapindaceae: poros pequenos, muito numerosos e em curtos múltiplos radiais, menos comumente solitários e racemiformes; elementos vasculares de comprimento médio; placas de perfuração simples; pontoações inter- vasculares areoladas, pequenas e alternas; parênquima paratraqueal-escasso; raios uni e bisseriados; fibras curtas, tipicamente septadas; e presença de cristais.

Apesar da predominância de raios homogêneos na família, Allophylus guraniticus apresenta raios heterogêneos. Esta característica, todavia, não constitui novidade, posto que Metcalfe \& Chalk (1972) já a havia mencionado como ocasional no gênero em questão. Baizhong et al. (1995) citam, igualmente, a presença de raios heterogêneos em Allophylus cobbe (L.) Raeusch.; raios parcialmente heterogêneos, por sua vez, foram registrados para Allophylus psilospermus Radlk. e Allophylus racemosus Sw. (León, 2010).

Baizhong et al. (1995) atribuem para a família a ocorrência generalizada de fibras libriformes. No presente estudo, contudo, foram observados fibrotraqueídeos na madeira, caráter assinalado, na literatura, apenas para outras duas espécies na família: Dilodendron bipinnatum Radlk. e Magonia pubescens St.-Hil. (Mattos et al., 2003).

De valor diagnóstico, salientam-se, ainda, a ocorrência de cristais romboédricos e de septos em fibras.

\section{REFERÊNCIAS BIBLIOGRÁFICAS}

BAIZHONG, L.; WELLE, B.J.H. Ter.; KLAASSEN, R.K.W.M. Wood anatomy of trees and shubs from China VII. Sapindaceae. IAWA Journal, v.16, n.2, p. 195-215, 1995.

BURGER, L.M.; RICHTER, H.G. Anatomia da Madeira. São Paulo: Ed. Nobel, 1991. 154 p.

DUJARDIN, E.P. Eine neue Holz-Zellulosenfaerbung. Mikrokosmos, n. 53, p. 94, 1964.

FREUND, H. Handbuch der Mikroskopie in der Technik. Frankfurt: Umsham Verlag, 1970.375 p.

JUDD, W. S.; CAMPBELL, C. S.; KELLOGG, E. A.; STEVENS, P. F.; DONOGHUE, M. J. Sistemática vegetal: um enfoque filogenético. Porto Alegre: Artmed, 2009. p. 438-440.

MARCHIORI, J.N.C. Comprovação da viabilidade da utilização da secção longitudinal tangencial para a determinação histométrica dos elementos axiais do xilema secundário. In: Anais do IV 
Congresso Florestal Estadual, Nova Prata, RS, p. 180-184, 1980.

MATOS, P.P; TEIXEIRA, L.L.; SEITZ, R.A.; SALIS, S.M.; BOTOSSO, P.C. Anatomia de madeiras do Pantanal Mato-Grossense (características microscópicas). Colombo: Embrapa Florestas; Corumbá: Embrapa Pantanal, 2003. p. 147-151.

METCALFE, C.R.; CHALK, L. Anatomy of the Dicotyledons. Oxford: Clarendon Press, 1972. p. 419-431.

RECORD, S. J.; HESS, R. W. Timbers of the New World. New Haven: Yale University Press, 1949. p 488-494.
SCHULTZ, A. R. Introdução ao estudo da Botânica Sistemática. Porto Alegre: Editora Globo, 1949. $426 \mathrm{p}$.

SOUZA, V.C.; LORENZI, H. Botânica Sistemática: guia ilustrado para identificação das famílias de Angiospermas da flora brasileira, baseado em APG II. Nova Odessa: Instituto Plantarum, 2008. p. 480-484.

WHEELER, E.A.; BAAS, P.; GASSON, P.E. IAWA list of microscopic features for hardwood identification. IAWA Bulletin, v.10, n. 3, p. 218359, 1989. 